\title{
Comparative Evaluation of Pot-in-Pot and Metal in Pot Evaporative Cooling Systems
}

\author{
Olaifa, 0. Peter, Osaguona, P. 0. \\ Department of Animal Production Technology, \\ Federal College of Wildlife Management, New Bussa, Nigeria
}

\begin{abstract}
How to cite this paper: Olaifa, O. Peter | Osaguona, P. O. "Comparative Evaluation of Pot-in-Pot and Metal in Pot Evaporative Cooling Systems" Published in International Journal of Trend in Scientific Research and Development (ijtsrd), ISSN: 24566470, Volume-3 | Issue-3 , April 2019, pp.952-954, URL: https://www.ijtsrd.c om/papers/ijtsrd23 218.pdf

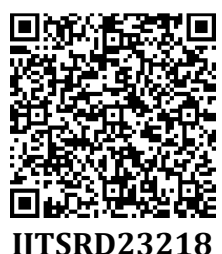

Copyright (C) 2019 by author(s) and International Journal of Trend in Scientific Research and Development Journal. This is an Open Access article distributed under the terms of the Creative Commons

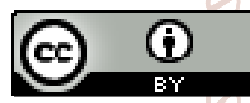
Attribution License (CC BY 4.0) (http://creativecommons.org/licenses/ by/4.0)

\section{INTRODUCTION}

Cooling through evaporation is an ancient an effective method of lowering temperature. Both plant and animal used this method to lower their temperature. Through the method of evapo-transpiration for example remains cooler than their environment.

The basic principle relies on cooling by evaporation. When water evaporates, it draws energy from its surrounding which produce a considerable cooling effect evaporative cooling occur when air is not too humid passes over a wet surface. The faster the rate of evaporative the greater cooler depends on the humidity of the surrounding air.

Evaporative cooling is dependent on the air it is necessary to determine the weather condition that may be encountered to properly evaluate the possible effectiveness of evaporative coolers Mentzer and Dale (1960) on the other hand the amount of water vapor that can be taken up and held by the air is not constant: it depends on two factors: the first is temperature (energy level) of the air, which determine the potential of the taken up and hold on water vapor. The second involve the availability of water, if little or no water is present, the air will be unable to take up very much.

The operational effectiveness of an evaporative cooler is made up of porous material. The water evaporates in to the air, razing the humidity and at the same time reducing the temperature of the air. The extent to which evaporation can be lower the temperature of the container depend on the different between the wet and dry bulb temperature, theoretically, it is possible to bring change in temperature equal to the difference in this two temperature. For example if the wet and dry bulb temperatures were $35^{\circ} \mathrm{C}$ and $15^{\circ} \mathrm{C}$ respectively the maximum drop of temperature due to the evaporative cooling would theoretically maximum temperature drop a substantial reduction in temperature is possible (Babarinsa, 2000).

Reduction in the temperature of fruits and vegetable stored in both pot in pot and iron in pot to retain spoilage is an important benefit of evaporative cooling. Though, it is not only one evaporation not only lowers the air temperature surrounding the produce, it also increase to moisture content of the air, this helps prevent the drying out of the produce and therefore, extend its shell life. Pot-in-pot are simple designs of evaporative coolers that can be used in the farm. The basic design a bigger pot that hold water, the inner pot and iron stored fruit and vegetable that is kept cool. One adaptation of the basic pot designs is the fermata cooler developed by the food and the nutrition board of India (Roy, 1985). A storage pot is placed in an earthen ware bowl 
containing water, the pot is then covered with a damp cloth that id dipped in to the water. Water drawn up the cloth evaporates keeping the storage pot cool; the bowl is also placed on wet sand to isolate the pot from the ground.

\section{Justification}

Due to the wide spread of poverty among rural farmers and insufficient power supply in developing countries like Nigeria, which contributes greatly to the loss of harvested agriculture produce requiring to meet fruitful future market, hence, there is need to fabricate tool that will preserve the agricultural perishables such as fruits and vegetable which is evaporative cooling system, therefore looking at effective E.C.S that will be more effective for farmers to store their farm product.

\section{Objectives}

To know which of the E.C.S can be used to extend the shelf life of vegetable and forages.

To determine the effect of temperature on the relative humidity on both pot in pot and metal in pot E.C.S.

\section{Materials and Methods}

Materials used for Pot in Pot and Metal in Pot include

$>$ Two larger earthen pot,small earthen pot and metal

$>$ Sand: which served as the permeable membrane.

$>$ Data measuring device such as: Soil thermometer and hygrometer

$>$ Lid: which serve as pot cover and also iron cover made of wood.

$>$ Water

$>$ Okra

\section{Research Location}

This project was carried out at federal college of wildlife management (FCWM) farm and research site under a tree located at the farm premises. The location is situated between kanji dam and new bussa town along awuru road. It lies between longitude $4^{0} 330 \mathrm{~N}$ and latitude $7031^{\circ} \mathrm{E}-10 \mathrm{E}$ (Onyeanusi, 1998).

\section{Climate}

The average monthly temperature of $34^{\circ} \mathrm{C}$ the highest value being $41^{\circ} \mathrm{C}$ with a mean annual relative humidity of $60 \%$ the average annual rainfall is $104.45 \mathrm{~mm}$.The first rainfall normally come in March reaches a peak in July to August and decline in September (Onyeanusi, 1998).

\section{Methodology}

Two different sizes of earthen pots were installed on a small hole. A small clay pot with bottom surrounded with polythene to prevent leakages was kept inside a bigger clay pot and the inter space was filled with river-bed sand which was made moist always by adding water thrice a day; In the morning, afternoon, and evening. The pot had a wooden cover. The thermometer and hygrometer were installed to take the record of temperature and relative humidity at interval of time for 14days.The same procedure was repeated in metal in pot but the smaller pot was replaced with 18 liter tin of kerosene as showing in figure 1.

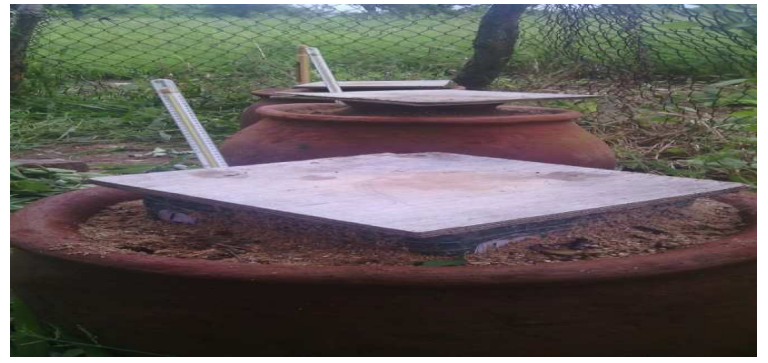

Figure 1: Diagrams showing pot in pot and metal in pot evaporative cooling systems

\section{Installation}

The two bigger clay pot are fixed on a small dung ground level and was filled with layers of river bed sand at the bottom and the smaller clay pot is inscribed in to the bigger clay pot likewise 18 litter kerosene tin was inscribed into the bigger pot filled with sand, the thickness of the first layer of sand in the base of the two bigger pots was adjusted so that the small pot and meta is at least $2 \mathrm{~cm}$ higher than the big pot to avoid water switching into the pots when irrigated. During this procedure the inner pot and metal stay exactly in the middle of the outer pot so that the distance between the pots is identical in all direction. When the sand fills the space between the pots to about $3 \mathrm{~cm}$ below the edges of the outer clay pots to allow space for wetting, the cooling system were installed and kept under a shade with adequate cross ventilation while wetting was one on regular basis.

\section{RESULTS}

The result obtained from the mean temperature and relative humidity of both evaporative cooling system is presented in Table 1. There were significant differences $(p<0.05)$ in the values of temperature recorded. The highest temperature for both ESC was recorded in the afternoon and the least in the morning; this is due to high intensity of the sun in the afternoon and cooling in the morning. Also, the highest relative humidity for both ESC was recorded in the morning due to high cooling effect.

Table 1: Temperature and relative humidity of pot in pot and metal in pot evaporative cooling systems

\begin{tabular}{|c|c|c|}
\hline & Temperature $\left({ }^{\circ} \mathrm{C}\right)$ & Relative humidity ( $\%$ ) \\
\hline \multirow[t]{2}{*}{$\mathrm{M}$} & $* 27.72$ & 97.43 \\
\hline & $* * 26.95$ & 73.27 \\
\hline \multirow[t]{2}{*}{$\mathrm{A}$} & $* 32.92$ & 47.08 \\
\hline & $* * 37.98$ & 45.24 \\
\hline \multirow[t]{2}{*}{$E$} & $* 29.68$ & 66.30 \\
\hline & $* * 28.76$ & 65.40 \\
\hline
\end{tabular}

\section{DISCUSSION}

Fresh Okra was stored in both ESC for a period of 14 days. The highest temperature was recorded in iron in pot (IIP) in the afternoon, this could be due to the fact that iron as a good conductor could transfer heat to the inner part of the storage device which in turns increases the temperature thereby reducing the inner relative humidity in the afternoon when intensity of the sun is maximum but overall cooling is achieved both in the morning and night. Evaporative cooling occurs when air, that is not too humid, passes over a wet surface, this implies that the faster rate of evaporation cooler depends on the humidity of the surrounding air. The vegetables being perishable, need immediate post-harvest attention to reduce the microbial load and increase their 
shelf life, which can be achieved by storing them at low temperature and high relative humidity conditions(Amat et al., 2013). Tha and Chopra (2006) reported that the cool chambers are able to maintain temperatures at $10-15^{\circ} \mathrm{C}$ below ambient, as well as at a relative humidity of $90 \%$ depending on the season. Evaporative cooling is an efficient and economical means for reducing temperature and increasing relative humidity of an enclosure and has been extensively tried for enhancing the shelf-life of horticultural produce (Tha and Chopra, 2006; Dadhich et al., 2008; Odesola and Oyebuchi, 2009) which is essential for maintaining the freshness of the commodities. The 14 days storage days recorded from this studies is less than 17 days shelf-life of okra reported by Longmone (2003), the observation made from this study shows that both ECS were effective but the inner pot replaced with metal in metal in pot increases the inner temperature thereby reducing the relative humidity which inturns increase the moisture content in metal in pot which increase the deterioration in metal in pot hence, there were little changes in color, freshness and less stronger than those stored in pot in pot, also relative humidity in pot in pot was more than metal in pot which increases the air flow movement in pot in pot, reducing the moisture content which enables the okra to remain fresher without any changes in color. Consequently, it was noted from this work that both ECS were not efficient for storing vegetables within the geographical location where this research was carried out due to an extremely high intensity of the sun, most especially during summer i.e. between February-June. More than $60 \%$ of the stored vegetables got perished.

\section{CONCLUSION}

The result obtained from this work showed that pot in pot ESC is more effective compared to metal in pot ESC for storing Okra but none is suitable for storing vegetables in New Bussa region of Niger state Nigeria and other places of equal climatic data and storage condition.

\section{RECOMMENDATION}

Since it was discovered from this work that temperature and air movement is the main factor that determine the shelf-life of Okra, it is therefore recommend that an artificial means of controlling temperature and humidity should be device so as to help farmers of the same climatic data store their vegetables.

\section{REFERENCES}

[1] AP-Tech. (1980)."A Village Food Cooler". AP-Tech Newsletter. 1:10-11.

[2] Akuffo, F.O. and K.D. Klorbortu. (1995). "Experiments of Food Storage in the Tropics Using Evaporative Cooling". VITA Documents. VIII-F-2; 013594.

[3] Anyawu, E. E. and Iwuagwu, C. J. (1995). Renew Energy. 6(2):125-8.

[4] Babarinsa, F. A. (1986). "Collection of Simple Evaporative Coolers for Low Cost preservation of Fruits and Vegetables". A paper presented at Nigeria and Stored Product Research Institute and In-house Review Meeting.

[5] Babarinsa, F. A. (2000). "A Jacketed Chamber Evaporative Cooler". A Design presented to the Nigeria Stored product Research Institute In-house. Review Meeting: Port-Harcourt, Nigeria.
[6] Appropriate Technology Journal. (1997). "Cooling your Cucumbers". Appropriate Technology Journal. 31(2, June):27.

[7] Dadhich SM, Dadhich H, Verma RC.(2008).Comparative study on storage of fruits and vegetables in evaporative cool chamber and in ambient. Int J Food Eng. 2008;4(1):1-11.

[8] Dunkle, R. V. (2005). "A Method of Solar Air Conditioning". Mechanical and Chemical Engineering Transactions of the Institutions of Engineers, Australia.7 (3, September).1-2.

[9] Hutchison, B. and Roger, C. (2000). "Inexpensive Evaporative Coolers for Short-term Storage of Food and Vegetables". A design study report. Mechanical Engineering Department, University of Texas at Arlington. May, 2000. VITA document. No. Viii-F-43000317.

[10] Jha SN, Chopra S. (2006). Selection of bricks and cooling pad for construction of evaporatively cooled storage structure. Inst Engineers (I) (AG); 87:25-28.

[11] Kitchen Trails. (2007). Food Chain.18 July 2007. IDTG.

[12] Lentz, C. P. (1985). "Temperature, Air Movement and Moisture less in Fresh Fruits and Vegetables Storage". Proc International Cong. Refrigeration.

[13] Longmone, A. P. (2003). "Evaporative Cooling of Good Products by Vacuum". Food Trade Review. (Pennwalt Ltd). 47:13-16.

[14] Mentzer, J. E. and Dale, A.C. (1960). "Evaporative Cooling of Animal Shelters". Journal of American Society of Agricultural Engineers.816-819, 821.

[15] Nease, H. C. (2007). "Cash Crop Field Heat Reduction in Perishables”. Agric. Food System International.161-163.

[16] Odigbo, E. U. (1994). "Storage Problems and Solutions Relative to Food Production and Distribution in Nigeria". Home Economics National Workshop. I. I. T. A.: Ibadan, Nigeria.

[17] Onyeanusi, J. B.(1998) Preliminary phase in the management, collection, interpretation and use of available environmental data, with special reference to Borgu game resources.

[18] Raha, A. Z., Rahim, A. A. A., and Elton, O. M. M. (1994). Renew Energy. 591: 474-476.

[19] Roy, S. K. and Khardi, D. S. (1985). "Zero Energy Cool Chamber". India Agricultural Research Institute: New Delhi, India. Research Bulletin No.43: 23-30.

[20] Ryall, A. L. and Pentzer, W. T. (1999). Handling Transportation and Storage of Fruits and Vegetables. Vol. 1 and 2. AVI Publishing Company: New York, NY. 29-35.

[21] Sharma and Rathi, R. B. (1991). "Few More Steps Toward Understanding Evaporating Cooling and Promoting Its use in Rural Areas". A Technical Report. Delhi, India. pp. 23.

[22] Singh, Mastiner and K. G. Naranyahgkeda. (1999). "Investigation and Development of Indirect Evaporative Cooling Using Plastic Heat Exchanger". Mechanical Engineering Bulletin. 14(7, June):61-65. 